University of Zurich

Department of Economics

Working Paper Series

ISSN 1664-7041 (print)

ISSN1664-705X(online)

Working Paper No. 6

The sources and magnitudes of Switzerland's gains from trade

Christian Hepenstrick

February 2011 


\title{
The sources and magnitudes of Switzerland's gains from trade
}

\author{
Christian Hepenstrick*
}

February 14, 2011

\begin{abstract}
This paper adapts the modern workhorse model of quantitative trade theory (Eaton and Kortum, 2002) as a measurement tool to quantify the magnitudes of Switzerland's gains from trade. I find that the importance of single trading partners for Switzerland's welfare is surprisingly small. The reason are reallocation effects - if trade between Switzerland and some partner country is inhibited, other supplier countries step into the breach so that the losses are limited. However, if one considers groups of countries, for example the EU, the welfare effects become large. In terms of policy this implies that whereas bilateral trade agreements may be important for particular industries per se, their relevance lies primarily in ensuring that the Swiss trade costs remain constant relative to trade costs within large trading blocks.
\end{abstract}

JEL classifications: F10, F11, F14

Keywords: Gains from trade, Switzerland, development accounting

\section{Introduction}

Switzerland is firmly integrated into the global trade network and the importance of international trade for Swiss prosperity is undisputed - witness for example the intensity at which movements in the EuroSwiss Franc exchange rate are debated in public. This paper asks where Switzerland's gains from trade originate from and of what magnitudes they are. In order to answer this question a model of the global trade network is indispensable. To see why consider an example: one observes in the data which goods are shipped from France to Switzerland at what quantities and prices. How would Swiss imports (and therewith Switzerland's welfare) change if Switzerland was not allowed to trade with France? Clearly, Switzerland would not simply stop to consume the goods previously sourced from France or start to produce all these goods locally. Rather would most other trading partners expand the range of goods

* Department of Economics, University of Zurich, email: christian.hepenstrick@econ.uzh.ch. I thank Philippe Ruh and Claudia Bernasconi for very helpful comments and discussions. 
they deliver to Switzerland since they now do not have to compete with France in supplying these goods; moreover the prices and quantities may change as well. Therefore, to assess the relevance of France for Switzerland's imports and welfare the observed trade pattern alone are not sufficient; a model describing the change of trade pattern associated with the counterfactual situation of no trade being possible between France and Switzerland is essential.

This paper adapts the workhorse model of modern quantitative trade theory as a measurement tool for the Swiss gains from trade. I quantify this model using data on global trade pattern from the year 2003. Within this quantified version of the model I can then assess the effects of experiments similar to the one described above on trade pattern and Swiss welfare. In particular I consider two types of experiments. The first experiments ask how Swiss welfare depends on trade (imports, exports, or both directions) between Switzerland and a particular trading partner being possible. The resulting equivalent variations are measures for how important a country is for Switzerland's gains from trade. The second experiment is concerned with the effects of European economic integration. I compare a situation of falling trade costs among EU27 countries with a situation where trade costs between Switzerland and the EU27 countries fall by equal amounts as they fall within the EU27. I obtain starkly differing predictions.

Previously Egger, Gassebner, and Lassmann (2009) and Mohler (2010) applied the methodology outlined in Feenstra (1994) to Switzerland. They measured by how much Switzerland's imported varieties grew over time and translated this into implied welfare gains (Mohler, 2010). This paper on the other hand quantifies a model of the global economy using cross-sectional data on trade flows and assesses the origins and magnitudes of Switzerland's gains from trade with counterfactual experiments within the quantified model. The advantage of this approach is its ability to capture general equilibrium effects such as changes in the global trade pattern and changing factor prices and price indices. Therewith I can not only assess observed changes, but also analyze hypothetical situations such as the ones discussed above.

Section 2 briefly outlines the model. Section 3 describes how I quantify the model. Section 4 presents the results and Section 5 provides a concluding discussion of the results.

\section{The Eaton and Kortum (2002) model as a measurement tool}

The Structure of the Model I adapt the quantitative Ricardian model due to Eaton and Kortum (2002) as described in Waugh (2010). ${ }^{1}$ In the following I briefly describe the model and refer the interested reader to Waugh (2010) for further details. The model describes a world of $N$ countries. A country $i$ is populated by $L_{i}$ agents each endowed with $h_{i}$ units of labor (human capital) and $k_{i}$ units of capital. Labor and capital are internationally immobile, but perfectly mobile within countries.

A competitive intermediate industry produces differentiated intermediate inputs that are internation-

\footnotetext{
${ }^{1}$ Waugh (2010) used the Ricardian model to assess how much of the cross-country variation in per-capita incomes is driven by asymmetries in trade costs.
} 
ally tradable using a Cobb-Douglas technology

$$
y(j)=z(j)\left(k(j)^{\alpha} l(j)^{1-\alpha}\right)^{\beta} q(j)^{1-\beta},
$$

where $q(j)$ is a CES aggregator over all intermediates $m \in[0,1] .{ }^{2}$ Productivity is country-variety specific and modeled as the realization of a Fréchet random variable

$$
\operatorname{Pr}\left[Z_{i}(j) \leq z\right]=\exp \left\{-T_{i} z^{-\theta}\right\}
$$

$T_{i}$ is country specific and governs the expected productivity draw (the higher $T_{i}$ the higher the expected productivity draw) and therefore represents country i's technology. Perfect competition and iceberg trade costs $-d_{n i} \geq 1$ units need to be shipped in $i$ for one unit to arrive at the destination market $n$ - imply that the price at which country $i$ offers variety $j$ in the destination market $n$ is $p_{n i}(j)=$ $d_{n i}\left(r_{i}^{\alpha} w_{i}^{1-\alpha}\right)^{\beta} P_{i}^{1-\beta} / z_{i}(j){ }^{3}$ The importing country $n$ sources any particular variety only from the country offering the best price. International trade therefore emerges whenever $p_{n n}(j)>\min _{i \neq n}\left\{p_{n i}(j)\right\}$.

The final goods industry is competitive and produces a homogenous non-tradable consumption good by bundling capital, labor, and intermediates using a Cobb-Douglas technology, $y_{F}=\left(k(j)^{\alpha} l(j)^{1-\alpha}\right)^{\gamma} q(j)^{1-\gamma}$, with an intermediate share $(1-\gamma)$.

The Equilibrium The model outlined above yields an instructive expression for real per-capita income in country $n$

$$
y_{n}=\left(\frac{T_{n}}{\Omega_{n}}\right)^{\frac{1-\gamma}{\beta \theta}} k_{n}^{\alpha} h_{n}^{1-\alpha},
$$

where $\Omega_{n}$

$$
\Omega_{n}=1-\sum_{i \neq n} \pi_{n i}
$$

$\pi_{n i}$ is the share of country $n$ 's total demand for tradables that is met by country $i$. (1) nicely summarizes the different determinants of a country's real per-capita income. As in a standard development accounting framework (see for example Caselli, 2005) real income depends on endowments, $h_{n}$ and $k_{n}$, the respective share $\alpha$, and TFP represented by $\left(T_{n} / \Omega_{n}\right)^{(1-\gamma) /(\beta \theta)}$. In contrast to the standard development accounting framework, however, TFP has a structural interpretation. Whereas $T_{n}$ is a truly exogenous technology parameter, $\Omega_{n}$ summarizes how much a country gains from trade.

To see this consider a country living in autarky. This country's trade shares are zero so that $\Omega_{n}^{\text {aut }}=1$. If this country opens up to trade, the trade shares become positive and therefore $\Omega_{n}<1$. The change in real income is given by $y_{n} / y_{n}^{a u t}=\Omega_{n}^{-(1-\gamma) /(\beta \theta)}$. In other words $\Omega_{n}^{-(1-\gamma) /(\beta \theta)}$ represents the equivalent

\footnotetext{
${ }^{2}$ The equilibrium wage rates, price indices, and trade pattern do not depend on the elasticity of substitution (see Alvarez and Lucas, 2007), which is why I omit further discussions of the details of the CES aggregator.

${ }^{3}$ Here and in the following I omit constants that will be irrelevant in the quantification for readability.
} 
variation with respect to autarky, i.e. the amount of income a country $n$ agent is willing to forgo in order to avoid autarky. More generally, I can assess welfare changes that are implied by any counterfactual situation (that does not affect $T_{n}, k_{n}$, and $h_{n}$ ) by considering the associated change in $\Omega_{n}^{-(1-\gamma) /(\beta \theta)}$.

In order to do that I compute the new trade shares, $\pi_{n i}$, and based on these the new $\Omega_{n}$. The trade shares' structural expressions are

$$
\pi_{n i}=\frac{\tilde{T}_{i}\left(w_{i}^{\beta} P_{i}^{1-\beta} d_{n i}\right)^{-\theta}}{\sum_{k=1}^{N} \tilde{T}_{k}\left(w_{k}^{\beta} P_{k}^{1-\beta} d_{n k}\right)^{-\theta}},
$$

where $w_{i}$ is country $i$ 's wage rate, $P_{i}$ is a CES price index and $\tilde{T}_{i}=T_{i}\left(h_{i} / k_{i}\right)^{-\alpha \beta \theta}$ is a country aggregator of endowments and technology that is unaffected by the counterfactual experiments performed later on. Sometimes I will refer to $\widetilde{T}_{i}$ as country $i$ 's "reduced form technology". The wage rates and the price indices are endogenous. The price indices are aggregates of the wages, technologies, price indices, and bilateral trade costs of all trading partners

$$
P_{i}=\left(\sum_{k=1}^{N} \tilde{T}_{k}\left(w_{k}^{\beta} P_{k}^{1-\beta} d_{i k}\right)^{-\theta}\right)^{-\frac{1}{\theta}}
$$

and the wage rates adjust such that every country's balance of trade equalizes ${ }^{4}$

$$
w_{n} h_{n} L_{n} \sum_{i \neq n} \pi_{n i}=\sum_{k \neq n} \pi_{k n} w_{k} h_{k} L_{k}
$$

The counterfactual experiments will consider changes in the global matrix of trade costs, $\left\{d_{n i}\right\}_{n, i}$. Given a quantified version of the model I will first calculate the implied changes of the equilibrium wage rates and price indices; then compute the implied trade shares and plug them into (1) to quantify the effect on welfare. For example I could set the bilateral trade costs between some country $n$ and a country $i$ to infinity, $d_{n i} \rightarrow \infty$. I then compute the unique set of wage rates that imply price indices and trade shares such that every country's balance of trade equalizes. ${ }^{5}$ Using the associated trade shares in (1) for country $n$ (country $i$ ) (based on the new trade shares) allows me to quantify how much country $n$ would be willing to pay in order to be able to import (export) from country $i$ (to country $n$ ). With experiments like this the model can be used as a measurement tool to find the sources and magnitudes of Switzerland's gains from trade.

\footnotetext{
${ }^{4}$ One can show that a country's total intermediate demand is proportional to this country's total labor income, which is why the balance of trade is written in terms of labor income.

5 The algorithm is implemented in MATLAB and uses a Tâtonnement-like iterative procedure as outlined in Alvarez and Lucas (2007). I start with a guess for the equilibrium wage rates. Based on this guess I solve for the price indices that are implied by (2). Using the wage rates and the corresponding price indices I compute the trade shares and check if all balances of payments equalize with these trade shares. I increase (decrease) the wages for countries with too large (low) exports and repeat this procedure until I find the equilibrium vector of wage rates. The program is available from the author upon request.
} 


\section{Quantifying the model}

The model's parameters are technologies, $\left\{\widetilde{T}_{i}\right\}_{i}$, trade costs, $\left\{d_{n i}\right\}_{n, i}$, population sizes, $\left\{L_{i}\right\}_{i}$, endowments, $\left\{h_{i}\right\}_{i}{ }^{6}$ and the parameters $\alpha, \beta, \gamma$, and $\theta$. In the following I outline my strategy to quantify these parameters. In that I follow closely Waugh (2010). I quantify the model based on data from the year 2003 and I use a sample of 86 countries, that together represent $87 \%$ of global GDP. ${ }^{7}$ Details on the data can be found in the Appendix.

I obtain the population sizes, $\left\{L_{i}\right\}_{i}$, from the World Development Indicators (World Bank, 2010) and the human capital endowments, $\left\{h_{i}\right\}_{i}$, from Caselli (2005). The parameters $\alpha=1 / 3, \beta=1 / 3, \gamma=3 / 4$, and $\theta=4.87$ I take from Waugh (2010). In a next step I model the unobserved trade costs as a function of observable variables

$$
-\theta \log d_{n i}=\delta_{k}+b+l+e x_{i}+\varepsilon_{n i}
$$

where I suppressed the associated dummy variables for expositional simplicity. $\delta_{k}(k=1, \ldots, 6)$ is the effect of the bilateral distance between countries $i$ and $n$ lying in the $k$ th distance interval. The intervals are (in miles): $[0,375),[375,750),[750,1500),[1500,3000),[3000,6000)$, and $[6000, \infty) . b$ is the effect of sharing a border and $l$ the effect of having the same language. $e x_{i}$ is an exporter fixed effect that allows for asymmetry in bilateral trade costs and $\varepsilon_{n i}$ captures all other barriers to trade and is assumed to be orthogonal to the exporter fixed effects, distance, border, and language. I then normalize the bilateral trade shares, $\pi_{n i}$, with the home shares of the importers, $\pi_{n n}$, to get $\pi_{n i} / \pi_{n n}=d_{n i}^{-\theta} S_{i} / S_{n}$, where $S_{i}=\tilde{T}_{i}\left(w_{i}^{\beta} P_{i}^{1-\beta} d_{n i}\right)^{-\theta}$. Taking logs and plugging in the trade cost function yields a gravity equation

$$
\log \left(\frac{\pi_{n i}}{\pi_{n n}}\right)=\delta_{k}+b+l+e x_{i}+\log S_{i}-\log S_{n}+\varepsilon_{n i}
$$

In order to empirically implement (3) I need data for $\pi_{n i} / \pi_{n n}, \delta_{k}, b$, and $l . \log S_{i}$ can be estimated as a country fixed effect and $e x_{i}$ as an exporter fixed effect. Note that the model restricts the country fixed effects $\log S_{i}$ and $\log S_{n}$ to be same for a given country, which is why one can identify the exporter fixed effect, $e x_{i}$. For the gravity variables on the right hand side $\left(\delta_{k}, b\right.$, and $\left.l\right)$ I use data from CEPII (2006). For the left hand side I construct the trade shares $\pi_{n i}$ following the methodology proposed by Eaton and Kortum (2002). It is important to note that the trade shares measure the value of a trade flow from $i$ to $n$ relative to the importer $n$ 's total absorption. Whereas it is straightforward to measure the total value of a trade flow using for example the COMTRADE database, total absorption has to be constructed. For that I first obtain the gross value of a country's manufacturing output from UNIDO (2003). I then subtract the total value of this country's exports to obtain this country's demand that is met by local producers. Adding total imports (from countries in the sample) yields the total value of this country's

\footnotetext{
${ }^{6}$ I do not need data on physical capital, $\left\{k_{i}\right\}_{i}$ since it is absorbed into the reduced form technologies, $\left\{\widetilde{T}_{i}\right\}_{i}$.

${ }^{7} \mathrm{I}$ choose the year 2003 since there is the largest number of observations of gross output in UNIDO (2003).
} 
demand, i.e. its absorption. Combining these with the values of the bilateral trade flows gives me the trade shares (the home share, $\pi_{n n}$, follows as a residual). Using these and the gravity variables I can estimate (3) with OLS. I thus obtain estimates for the trade costs, $d_{n i}$, and the country fixed effects, $S_{i}$.

Having obtained estimates for the trade costs, the remaining elements of the model that need to be quantified are the countries' reduced form technologies, $\left\{\widetilde{T}_{i}\right\}_{i}$. Remember that the country fixed effects are $S_{i}=\tilde{T}_{i}\left(w_{i}^{\beta} P_{i}^{1-\beta} d_{n i}\right)^{-\theta}$. I have estimates for the trade costs and the fixed effects. Given values for the wage rates and the price indices I thus could solve for the implied reduced form technologies. For that I first get the price indices (up to an irrelevant constant) by combining the estimated fixed effects, $S_{i}$, and the trade costs, $P_{n}=\left(\sum_{i=1}^{N} S_{i} d_{n i}^{-\theta}\right)^{-1 / \theta}$. In a next step I obtain the wage rates. I choose $w_{1}$ as the numéraire and rewrite the balances of payments for the countries $n=2, \ldots, N$ as $w_{n}=\pi_{1 n}\left(h_{1} L_{1}\right) /\left(h_{n} L_{n}\right)+\sum_{k=2}^{N} \pi_{k n} w_{k}\left(h_{k} L_{k}\right) /\left(h_{n} L_{n}\right)$. Stacking these equations I get a linear system

$$
\left[\begin{array}{cccc}
1-\pi_{22} & -\pi_{32} \frac{h_{3} L_{3}}{h_{2} L_{2}} & \cdots & -\pi_{N 2} \frac{h_{N} L_{N}}{h_{2} L_{2}} \\
\vdots & \ddots & \ddots & \vdots \\
-\pi_{2 N} \frac{h_{2} L_{2}}{h_{N} L_{N}} & \cdots & -\pi_{(N-1) N} \frac{h_{(N-1)} L_{(N-1)}}{h_{N} L_{N}} & 1-\pi_{N N}
\end{array}\right]\left[\begin{array}{c}
w_{2} \\
\vdots \\
w_{N}
\end{array}\right]=\left[\begin{array}{c}
\pi_{12} \frac{h_{1} L_{1}}{h_{2} L_{2}} \\
\vdots \\
\pi_{1 N} \frac{h_{1} L_{1}}{h_{N} L_{N}}
\end{array}\right]
$$

Since I have data on the labor endowments, $h_{n} L_{n}$, and the constructed the trade shares, $\pi_{n i}$, I can solve for the unique set of wage rates that is implied by this system. Using these together with the previously constructed price indices and the country fixed effects I can back out the technologies, $\widetilde{T}_{i}=$ $S_{i}\left(w_{i}^{\beta} P_{i}^{1-\beta} d_{n i}\right)^{\theta}$

\section{The Swiss gains from trade}

Having fully quantified the model, I can now turn to the question of this paper. Where do the Swiss gains from trade originate from and how large are they?

Gains from trade; country by country One can obtain a first idea on the origins of Switzerland's gains from trade from equation (1) alone. Clearly, countries with higher trade shares with Switzerland contribute more to $\Omega_{n}$. Table 1 presents the thus obtained 10 top sources of gains from trade for Switzerland.

Table 1

The ranking is based on trade shares in non-consumption manufactures since the model is one of trade in intermediates - all subsequent results are based on non-consumption manufactures. However, the results are very similar (within 1-2\%) if we use only intermediates or total trade instead since the corresponding trade shares are highly correlated. Switzerland's top origins of gains from trade are the ones one would expect ex ante - close European neighbors and the two large countries, USA and China (Japan ranks 
11 th).

However, note that the trade shares do not directly mirror the quantitative relevance of a given country for Switzerland's gains from trade. Imagine for example a situation where a particular country, say Germany, was not allowed to trade with Switzerland. Setting the share of Germany in Switzerland's imports to zero in equation (1) and using the associated change in $\Omega_{n}$ as a measure of Switzerland's welfare change would assume that all the varieties that had previously been sourced from Germany are now produced locally (in Switzerland). But this is of course not what happens, since most varieties will now simply be sourced from other foreign countries. This is where the structural model becomes relevant - the reallocation effects can only be quantified based on a general equilibrium model.

Table 2 presents model-based estimates for the magnitudes of Swiss gains from trade with particular countries. I perform three types of experiments; Column 3 presents the welfare change associated with inhibiting exports from Switzerland to a given country $\left(d_{n, C H} \rightarrow \infty\right)$; Column 4 presents the welfare changes when imports are inhibited $\left(d_{C H, n} \rightarrow \infty\right)$; and Column 2 represents the welfare changes when both - imports and exports - are inhibited $\left(d_{C H, n}=d_{n, C H} \rightarrow \infty\right)$.

\section{Table 2}

For comparison Column 5 present the "naive" estimates, that simply set the bilateral trade share in (1) to zero. Clearly, the "naive" estimate strongly overstates the gains associated with being able to trade with particular countries. This is because the reallocation effects, i.e. importers sourcing varieties in other foreign countries, are strong. For example, let's consider a situation where imports from the United States are inhibited. The "naive" estimate would simply say that the Swiss home share rises by the United States' trade share, which corresponds to a $10 \%$ increase in the home share. In contrast, if we account for the reallocation effects using the general equilibrium model, we find that the home share only increases by $1 \%$, since most goods that have been previously imported from the US are now delivered by other countries, in particular European neighbors. Correspondingly, the associated welfare loss is much smaller.

A second finding is, that generally, the welfare gains from being able to import from a country are larger than the gains from being able to export to this country (except for Canada and Germany). The gains from being able to import come mainly from lower prices, which translate into lower unit costs in the production of both final goods and intermediates. The lower unit costs in intermediates in turn increase demand for Swiss production factors and therewith their remuneration. The gains from being able to export to a country are due to an increased demand for local production factors and the associated increase in their remuneration. The Swiss price index, however, is almost unaffected.

A third finding are the rather small gains from trade. Except for the immediate large neighbors 
Germany, France, and Italy, the equivalent variation lies below $1 \%$ of the income in the initial situation. This result is again related to the strong reallocation effects. Were we to consider only finite increases in the trade costs, the results would even be smaller. This implies that the gains from trade agreements such as the one currently negotiated with China may be overstated in the public debate. However, a second class of counterfactual experiments demonstrates that whereas changes in bilateral trade costs do not matter too much, multilateral changes in trade costs matter very much for Switzerland's welfare.

The welfare effects of a further European integration A second instructive experiment is concerned with the (indirect) effects of the European integration on Switzerland. Consider for example the calibrated 2003 world. What is the welfare effect on Switzerland if the trade costs among EU27 countries uniformly decrease by $25 \%$ ? To put this in perspective, Anderson and Van Wincoop (2004) put the average trade costs among OECD countries at around $d_{n i}=1.7$. A 25\%-reduction thus is a significant step towards free trade with the new average trade costs lying around 1.27. There are three channels how this reduction in trade costs affects Swiss welfare. First, the lower trade costs among EU27 countries implies that the price indices in these countries decrease. Therefore the prices of Switzerland's imports decrease as well, which is good for both intermediate and final goods production. Second, the lower trade costs imply that EU27 production factors are now more productive, so that their remuneration rises, which in turn tends to increase the prices of Switzerland's imports. Third, since the trade costs between EU27 countries and Switzerland are now larger relative to within-EU27 trade costs, EU27 demand is diverted away from Switzerland - for example there are varieties that Germany previously sourced from Switzerland but now, due to lower intra-EU27 trade costs buys from France. This reduces demand for Swiss production factors and therefore lowers the Swiss factor remunerations.

The total effect on Swiss welfare is a decrease in welfare by $3 \%$, i.e. the falling factor remunerations due to lower demand for Swiss goods and the tendency for higher import prices due to higher factor prices in the EU27 dominate the tendency for lower prices due to falling price indices in EU27 countries. How strong are these channels separately? In order to assess the effects on Swiss import prices I first compute the Swiss price index (2) keeping the wage rates constant but using the new (lower) price indices of the trading partners. This leads to a decrease of $5 \%$ in the price index. If one, on the other hand, keeps the price indices of the trading partners constant, but uses the new (higher) wage rates one gets an increase in the price index of $8 \%$. Taken together, the latter effect dominates and the Swiss price index increases by around 3\%. The third effect is trade being diverted away from Switzerland. This leads to a $8 \%$ decrease of factor incomes. Together, the higher price index and the lower incomes in Switzerland translate into fall in welfare of $3 \%$.

The situation looks very different if Switzerland participates in the trade liberalization. With respect to the Swiss price index we now have three effects - the lower trade cost, the higher wage rates, and the 
lower price indices of EU27 countries. Using the old wage rates and price indices together with the new trade costs in (2) leads to a decrease of the Swiss price index by $6 \%$. With the old trade costs and the old wage rates, but the new EU27 price indices we have a fall of $5 \%$. And if we keep the trade costs and the price indices constant, but use the new wage rates the price index would rise by $9 \%$. Together these effects imply a decrease of the Swiss price index by around 1\%. Moreover, since the trade costs between Switzerland and the EU27 countries have now fallen by similar amounts as the intra-EU27 trade costs demand is not diverted away from Switzerland. And the lower trade costs also imply that factors are now more productive. Correspondingly the Swiss factor remunerations increase - nominal incomes increase by $44 \% .^{8}$ Together with the lower price index this translates into a $10 \%$ increase in real income and thus in welfare.

\section{Concluding discussion}

This paper adopted the Ricardian multi-country trade model as a tool to measure the Swiss gains from trade with particular countries. It did so by performing counterfactual experiments within a quantified version of the trade model. The advantage of this approach is its ability to account for general equilibrium effects. I found that besides Switzerland's immediate neighbors most countries' contribution to Swiss welfare is surprisingly small - the reason for this result are strong reallocation effects. In a second experiment I found that a large fall in trade costs within the EU leads to a relatively minor welfare loss in Switzerland. If, however, Switzerland would lower its trade costs with the EU simultaneously, this loss would turn into a relatively large welfare gain.

What can we learn from these results? The first experiments yield only small gains from being able to trade with particular countries. Why then should Swiss policy makers bother to negotiate bilateral free trade agreements such as the one recently initiated with China (Seco, 2011)? Clearly, whereas the welfare gain for the average Swiss citizen is likely to be small, particular industries may gain a lot. More importantly, there is a general tendency for falling trade costs due to policy decisions such as free trade agreements. In the light of the second experiment it is important to avoid a relative rise in Swiss trade costs. Whereas the gains from bilateral free trade agreements may be small per se, they can be an important element in a strategy that seeks to keep relative trade costs vis-à-vis other countries constant. When global trade costs are generally falling this promises relatively large gains for Switzerland. To summarize, it is always desirable to lower trade costs with trading partners; however, if large trading blocks increase their integration by lowering within-block trade costs it is crucial and of great economic benefit if the Swiss keep relative trade costs constant by lowering the bilateral trade costs with the block.

\footnotetext{
${ }^{8}$ This number seems to be very high at a first sight. However, note that nominal wages here imply relative to the numéraire wage, $w_{1}$, which is the US wage rate in my implementation. The US wage rate in turn falls since they do not participate in the trade liberatlization. Secondly, as mentioned above, a $25 \%$ reduction in intra-EU27 trade costs is a significant step towards free trade and the wage gains are correspondingly large.
} 


\section{References}

Alvarez, F., AND R. LucAs (2007): "General equilibrium analysis of the Eaton-Kortum model of international trade," Journal of Monetary Economics, 54(6), 1726-1768.

Anderson, J., And E. VAn Wincoop (2004): "Trade costs," Journal of Economic Literature, 42(3), $691-751$.

Barro, R., And J. LEE (2001): "International data on educational attainment: updates and implications," Oxford Economic Papers, 53(3), 541-563.

CASElli, F. (2005): "Accounting for cross-country income differences," in Handbook of Economic Growth, ed. by P. Aghion, and F. Durlauf, pp. 679-741. Elsevier.

CEPII (2006): CEPII databases - distances. Centre d'Etudes Prospectives et d'Informations Internationales.

Eaton, J., And S. Kortum (2002): “Technology, geography, and trade," Econometrica, 70(5), 17411779.

Eaton, J., S. Kortum, and F. Kramarz (2004): "Dissecting trade: firms, industries, and export destinations," American Economic Review, 94(2), 150-154.

Egger, P., M. Gassebner, and A. Lassmann (2009): "Armington product variety growth in small versus large countries," Swiss Journal of Economics and Statistics, 145(4), 411-419.

Feenstra, R. (1994): "New product varieties and the measurement of international prices," American Economic Review, 84(1), 157-177.

Gaulier, G., S. Zignago, D. Sondjo, A. Sissoko, and R. Paillacar (2010): "BACI: a world database of international trade at the product-level, 1995-2007 version," Centre d'Etudes Prospectives et d'Informations Internationales Working Paper No. 2010-23.

Mohler, L. (2010): "Variety Gains from Trade in Switzerland," mimeo.

SECO (2011): "Memorandum of understanding between the Federal Department of Economic Affairs of the Swiss Confederation and the Ministry of Commerce of the People's Republic of China on launching the negotiations for a Switzerland-China free trade agreement," available at: http://www.news.admin.ch/NSBSubscriber/message/attachments/21944.pdf.

UNIDO (2003): Industrial statistics database. United Nations Industrial Development Organization.

Waugh, M. (2010): "International trade and income differences," American Economic Review, forthcoming. 
World BANK (2010): World development indicators. World Bank. 


\section{A Data}

The sample consists of 86 countries that together represent $87 \%$ of global GDP. This gives rise to $7310=86 * 85$ bilateral trade relations. In the following I describe the data used to quantify the model. I use the trade shares for non-consumption goods. Alternatively one could use total trade or trade in intermediates only. The results do barely change since the shares are highly correlated.

\section{A.1 Aggregate values of bilateral trade flows}

I use COMTRADE data for 2003 as provided by CEPII (Gaulier, Zignago, Sondjo, Sissoko, and Paillacar, 2010). This data provides the dollar values of the bilateral trade flows between 239 economic entities (mostly countries) on the HS6 level of aggregation. Summing over all HS6 categories of non-consumption goods yields the total value of a bilateral trade flow.

\section{A.2 Gross output and manufacturing absorption}

I use data from the United Nations Industrial Development Organization (UNIDO, 2003) on gross manufacturing output. For the year 2003 this database provides the gross manufacturing output for 77 countries. Unfortunately, the database does not include gross output for several large countries, most notably Switzerland and China. I therefore choose to impute the gross manufacturing output for countries that belong to the 20 largest economies in 2003 and for which I do not observe gross manufacturing output. I do this by following Eaton, Kortum, and Kramarz (2004) and scaling value added in the manufacturing sector by the average ratio of gross output and value added across countries. Using bilateral trade flows I transform the gross output into total manufacturing absorption as described in the main text. To get at the manufacturing absorption in non-consumption goods only, I proxy their shares in gross output by the shares in a country's total exports.

\section{A.3 Bilateral distances, shared border, and common language}

All transportation cost proxies are from the database provided by CEPII (CEPII, 2006). The bilateral distance is measured as the distance between two countries' most populous cities. The common language indicator takes the value one if two countries have the same official language ${ }^{9}$ and common border takes the value one if two countries share a common land-border.

\section{A.4 Endowments and population sizes}

Human capital $h_{i}$ is taken from Caselli (2005) who uses the data of Barro and Lee (2001). These authors compute human capital as a piece-wise log-linear function of average years of schooling of a country's

\footnotetext{
${ }^{9}$ The results remain basically unchanged when using major languages instead of official languages.
} 
population over 25 year. Population sizes are taken from the Worldbank's World Development Indicators (World Bank, 2010). Note that I do not need data on physical capital stocks, since they are absorbed into the reduced form technology term, $\widetilde{T}_{i}$. 
Table 1: Ranking of contributions to Switzerland's gains from trade based on observed trade shares

\begin{tabular}{lcc}
\hline country & rank & share \\
\hline Germany & 1 & 14.9 \\
Italy & 4 & 4.0 \\
France & 3 & 4.3 \\
United States & 2 & 4.4 \\
Austria & 6 & 2.0 \\
Netherlands & 7 & 2.0 \\
United Kingdom & 9 & 1.5 \\
Ireland & 5 & 2.5 \\
Belgium and Luxembourg & 8 & 1.6 \\
China and Hongkong & 10 & 1.2 \\
\hline
\end{tabular}

Table 2: Welfare losses associated with inhibited trade with top 10 trading partners

\begin{tabular}{lcccc}
\hline trading partner & no trade & no exports & no imports & "naive" estimate \\
\hline Germany & 7.9 & 4.9 & 3.3 & 19.0 \\
France & 5.1 & 2.1 & 3.2 & 18.6 \\
Italy & 4.5 & 1.8 & 3.0 & 17.8 \\
United Kindom & 0.6 & 0.2 & 0.4 & 4.0 \\
Belgium and Luxembourg & 0.5 & 0.2 & 0.3 & 3.1 \\
Austria & 0.4 & 0.2 & 0.3 & 2.7 \\
The Netherlands & 0.3 & 0.1 & 0.2 & 2.3 \\
Spain & 0.3 & 0.1 & 0.2 & 2.3 \\
United States & 0.2 & 0.1 & 0.1 & 1.4 \\
China & 0.1 & 0.0 & 0.1 & 0.9 \\
\hline
\end{tabular}

